\title{
Stenting a persistent ductus arteriosus - an ongoing interventional story
}

\author{
Anca loana Sglimbea', Liliana Gozar ${ }^{1,2}$, Tibor Mezei², László Hadadi ${ }^{*}$
}

\begin{abstract}
Stenting the patent ductus arteriosus is an old procedure which only lately has shown its advantages at its highest potential. Objective - To apprehend the arterial duct stenting procedure, its history, change over time and present usefulness and technique. Methods and results - We present the first two cases of stent implantation in a persistent ductus arteriosus performed in our institution and a short review of the literature on this subject, connecting our small experience to that of other centers. Conclusions - Stent implantation in the ductus arteriosus is of great help in knowledgeable hands and minds. While it needs a learning curve, careful preparation before introducing it in the daily practice of a cardiovascular center is essential.
\end{abstract}

Keywords: patent ductus arteriosus, stenting, child.

Rezumat: Stentarea canalului arterial este o procedură cunoscută de multă vreme care însă a ajuns doar recent să își demonstreze avantajele și să-și atingă potențialul maxim. Obiectiv - Să înțelegem procedura de stentare a canalului arterial, istoria ei, modificările apărute în timp, utilitatea ei în prezent și tehnica folosită. Material și rezultate - Prezentăm primele două cazuri de stentare de canal arterial efectuate în instituția noastră și revedem literatura pe aceasta temă, conectând mica noastră experiență la cea a altor centre. Concluzii - Procedura de stentare a canalului arterial este de mare ajutor în mâini și minți avizate. Are nevoie de o curbă de învățare iar pregătirea atentă înainte de a introduce aceasta procedură într-un centru este de maximă importanţă.

Cuvinte-cheie: canal arterial, stentare, copil.

\section{INTRODUCTION}

Surgical possibilities for palliative or stepwise treatment of cyanotic congenital heart diseases (cCHD) haven't changed very much since Blalock and Taussig performed the first systemic- to- pulmonary shunt, in the 1940's. Interventional cardiology has followed in the steps of surgery, seeking for its own methods. But, unlike other interventional therapies, which became shortly after initiation well established procedures, equal or superior to surgery, this procedure has a much complicated history. First performed by Gibbs in 1991', it was only in the 2010's, after more detailed understanding of the functioning of the persistent ductus arteriosus (PDA) and appearance of more performant interventional materials, borrowed from coronary interventions, that stenting the PDA became an option to surgery.

\footnotetext{
' Emergency Institute for Cardiovascular Diseases and Transplantation, Targu Mures, Romania

2 Department of Pathology, „George Emil Palade” University of Medicine, Pharmacy, Science and Technology, Targu Mures, Romania
}

There are 3 major groups of diseases that can benefit from stenting the PDA:

I. cCHD with duct-dependent pulmonary circulation

2. cCHD with duct-dependent systemic circulation

3. Idiopathic pulmonary arterial hypertension (idiopathic aPHT)

Stenting the PDA is a complex procedure, needing a learning curve and a very careful case selection. Moreover, for a catheterization laboratory with a limited choice of available materials, this procedure has to be planned and implemented stepwise, from case selection, careful preprocedural planning of the intervention under all aspects (anesthesia and intensive care, vascular access, technique), to postprocedural follow-up.

We present the first two cases of PDA stenting performed in our clinic, discussed in the context of

\footnotetext{
Contact address:

László Hadadi, Emergency Institute for Cardiovascular Diseases and Transplantation, 50 Gheorghe Marinescu Street, 540136, Targu Mures, Romania.

E-mail: hadadilaci@yahoo.com
} 
the present literature in the field, and propose in the same time an algorithm for establishing indication, selecting cases and stepwise implementation of this difficult, but very useful, once mastered, procedure.

\section{CASE I (CCHD WITH DUCT- DEPENDENT PULMONARY CIRCULATION)}

Patient KAM, 5-month old male infant, was transferred to our clinic from another university facility, after being admitted there for a severe and prolonged hypoxic spell with loss of consciousness. The patient was known since birth with tetralogy of Fallot with pulmonary atresia (TF-PA), hypoplastic pulmonary branches and a PDA.

On arrival he was in a severe condition, with generalized cyanosis, arterial oxygen saturations in the $60 \%$ range while intubated and ventilated with $100 \%$ oxygen. Cardiac ultrasound and computed tomography angiography (CTA) show a rare form of TF-PA, with a right aortic arch and the PDA rising from the branching of the left subclavian artery from the left sided brachiocephalic trunk. PDA had a significant stenosis, located in the middle third of its length.

Under the circumstances, the decision was made to interventionally implant a stent in the stenotic PDA. The procedure has been carried out under general anesthesia, with two vascular access points: a $5 \mathrm{Fr}$ sheath in the left femoral vein and a $4 \mathrm{Fr}$ sheath in the left femoral artery (changed afterwards for a $35 \mathrm{~cm}$ long $5 \mathrm{Fr}$ sheath). Based on the obtained measurements (PDA diameter above the stenosis: CTA - 5.3-5.4 $\mathrm{mm}$, invasive angiography $-4.8 \mathrm{~mm}$; PDA diameter below the stenosis: CTA - 4.7-5.3 mm, invasive angiography $-4.6 \mathrm{~mm}$ ), a $5.0 \times 15 \mathrm{~mm}$ Resolute OnyxTM premounted drug eluting stent (Medtronic, CA, USA) was chosen and eventless implanted (Figure I). Arterial saturations immediately rose from $60 \%$ to over $80 \%$ and the child could be extubated the next days.

Afterwards, at the age of 6 month ( 2 weeks after the interventional procedure), an elective total corrective surgery was performed: patch closure of the ventricular septal defect (VSD), placing a valved conduit between the right ventricle (RV) and the pulmonary artery (PA), and PDA closure with stent explantation.

\section{Discussion}

Cyanotic congenital heart diseases with duct- dependent pulmonary circulation are neonatal emergencies, necessitating therapy in the first weeks of life. Therapy consists of securing a reliable and stable source of pul- monary blood flow by means of either a systemic-topulmonary Blalock-Taussig shunt (BTS), or, recently, stenting the PDA.

Mortality of the BTS, as reported recently by the Society of Thoracic Surgery ${ }^{2}$, is, with $7.2 \%$, relatively high. For PDA stenting, the reported mortality is extremely variable, between $3.6-31 \%^{3}$. This variability is mainly caused by the anatomical heterogeneity of the disease and the necessity of a learning curve. Recent studies have shown advantages of stenting the PDA compared to BTS: less invasive, avoidance of neonatal cardiac surgery, better and more symmetrical development of the pulmonary vascular bed, better postprocedural stability, shorter intensive care and in-hospital stay. At the same time, survival to the next surgical step isn't inferior to BTS 4 .

It is, nevertheless, a complex procedure, needing a learning curve and with multiple potential complications. These are also reflected by the indications of PDA stenting, as released by the American Heart Association in 201 I: stenting the PDA in a CCHD with duct- dependent pulmonary flow in which the PDA is the collateral source for pulmonary flow is Class lla indication with level of evidence $B$, while stenting the PDA when it is the single source of pulmonary flow is Class Ilb indication with a level of evidence C. The same guideline establishes as a contraindication (Class $C$ indication) stenting the PDA in the presence of a proximal pulmonary branch stenosis in its vicinity ${ }^{5}$. Recent studies and case reports define even more risk factors: weight under $2.5 \mathrm{~kg}$, very tortuous PDA and insufficient restricted pulmonary end $(>3 \mathrm{~mm})^{4}$.

Success resides in proper selection of cases, detailed preparation of the procedure and the availability of needed materials.

\section{Proper case selection}

This is based on the exact definition of the anatomy of the PDA. Accordingly, data one must know about the PDA are: the type of aortic origin (located anywhere from the proximal descending aorta to the origin of the brachiocephalic trunk), its form (straight, tortuous, long, or short), and the location of pulmonary insertion (at the roof of the PA trunk or towards the origin of the left PA - when there is an increased risk for left pulmonary branch stenosis).

By these criteria, there are 4 main categories ${ }^{6,7}$ :

a. PDA originating from the proximal descending aorta (similar to the isolated PDA), usually of conical shape (very similar to category A of the Krichenko classification), short and without tor- 


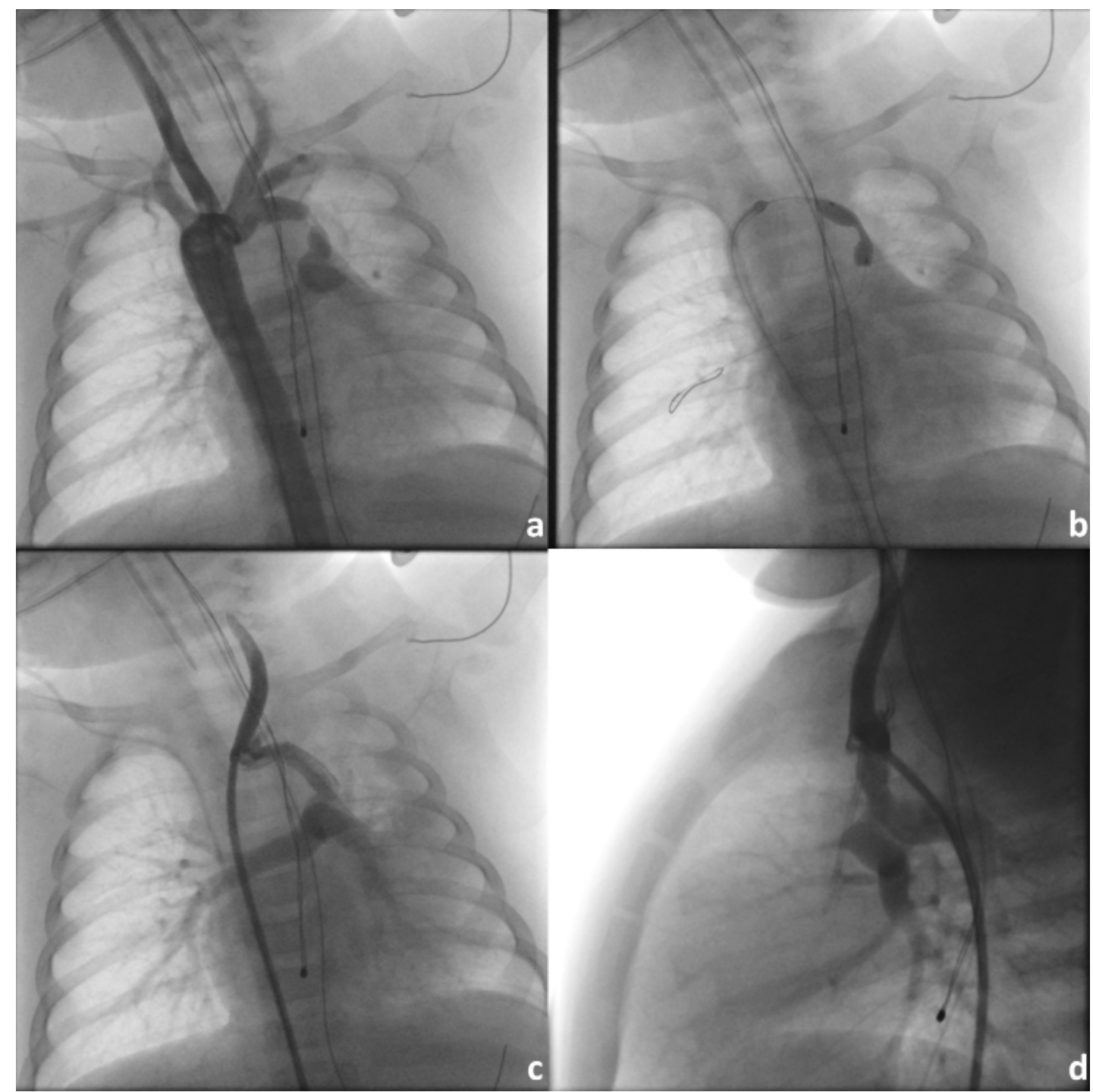

Figure I. Angiograms of patient I. Patent ductus arteriosus arising from the left subclavian artery with a stenosis in the middle part (a); stent implantation in the stenosis (b); postprocedural aspect in postero-anterior (c) and latero-lateral angiographic projections (d).

tuosity, opening into the roof of the PA, usually without causing stenosis of pulmonary branches. This category encompasses most cases of pulmonary atresia with intact ventricular septum (PAIVS), critical pulmonary stenosis, tricuspid atresia, d-transposition of the great arteries (d-TGA), and Ebstein disease with functional pulmonary atresia.

b. PDA with origin form the middle portion of the inner side of the aortic arch (vertical ductus), visà-vis to the origin of the left subclavian artery, the left common carotid artery, or the brachiocephalic trunk. These PDA's have a vertical trajectory, often making a kinking before opening towards the origin of the left PA and, thus, ha- ving an increased risk of causing a left PA branch stenosis (due to PDA tissue infiltrating into the left PA). This category includes TF-PA and other forms of more complex cCHD (TGA with VSD and pulmonary atresia or single ventricles with pulmonary atresia).

c. PDA with intermediate origin, between the classic and the vertical one. These PDA's tend to be longer and more tortuous, especially towards their opening into the roof of the PA. This category includes some forms of PA-IVS.

d. PDA's with origin form the subclavian artery (SA). These are very rare forms of PDA, less than $5 \%$ and their shape resemble remarkably to a surgically performed BTS. The origin is from the 
left SA in case of a right aortic arch and from the right SA if there is a left-sided aortic arch. These are straight and relatively long PDA's, rising in a 90-degree angle form the SA and opening, usually with a stenosis, into the ipsilateral PA branch. Most of the cases in this category are TF-PA.

Our patient can be included in the rare group of tetralogy of Fallot cases with pulmonary atresia and a PDA arising from the left subclavian artery (category d). But slightly different from the general model described in the literature, its origin was rather from the origin of the SA from the left-sided brachiocephalic trunk, and this PDA had also a localized stenosis in the middle third of its length. This was probably the anatomic peculiarity that determined the relatively late presentation with severe desaturation.

\section{Preparation of the procedure and necessary materials}

Often, especially in less well supplied laboratories, it is wise and recommended to perform a CTA scan prior to the stenting procedure, to gather all the anatomical data $^{8}$. This is also the case in our clinic, CTA being part of the pre-treatment assessment of the patients with a cCHD with duct dependent pulmonary blood flow.

Vascular access is chosen based on the anatomy of the PDA, i.e. by selecting the easiest and most straightforward way to enter the PDA and secure the guidewire in a PA branch. According to the previously described four anatomical categories (a-d), the most adequate vascular approach is:

a. retrograde, from the descending aorta (sheath in the femoral artery)

b. anterograde, from the right heart (sheath in the femoral vein) $+/$ - femoral artery cannulation for angiograms. Variants are surgical cut-down of the ipsilateral carotid artery, or a sheath placed in the ipsilateral SA

c. retrograde, from the descending aorta (sheath in the femoral artery)

d. retrograde, from the descending aorta (sheath in the femoral artery) ${ }^{9}$.

Correspondingly, retrograde access by placing a sheath in the femoral artery offered the easiest pathway for our patient.

Another difficult choice in the typical patient with cCHD with duct dependent pulmonary circulation is the most proper moment to stop prostaglandin infusion (PGEI), to obtain a sufficient reduction of the PDA diameter for secure stent anchoring (pulmonary end diameter $<3 \mathrm{~mm}$ ). We didn't encounter this problem, as our patient was relatively “old” and PGEI wasn't an option from the beginning.

The choice of the stent type (coronary or other types, bare metal, or drug-eluting) is mainly related to operator preferences and local availability. More important is choosing a stent that covers the whole length of the PDA ${ }^{3}$. The smallest part of the PDA that remains uncovered can cause (re)stenosis. It is equally important that the stent does not cause obstruction of the PA branches. That is the reason why recognition of situations with the potential of evolving towards stenosis of the PA branches is important before choosing a type of treatment ${ }^{6}$. Nowadays there are several centers and groups who have developed techniques of stent implantation even in situations at risk to evolve with PA branch stenosis, but with the expense of higher reintervention- or early surgical correction rates s.10-12. $^{7}$.

The stent has to be chosen a few millimeters longer than the length of the PDA (which is relatively easy in a straight PDA, but can be sometimes tricky in a tortuous one $)^{3}$. If the stent is not long enough, a second one can be implanted using the overlapping technique (which is preferable to a too long stent).

The diameter to which the stent is dilated depends on the weight of the child, the period for which patency of the stent is required, and the operator preference. Generally, the stent should be dilated to 3.0-3.5 $\mathrm{mm}$ in children who weigh less than $3 \mathrm{~kg}$, to $3.5-4.0$ $\mathrm{mm}$ in children with weights between $3-4 \mathrm{~kg}$, and to more than $4.0 \mathrm{~mm}$ in children over $4 \mathrm{~kg}^{3}$. For our patient, who had $5.3 \mathrm{~kg}$, we selected a drug eluting coronary stent (which we had on the shelf) of $5.0 / 15 \mathrm{~mm}$.

We have chosen to cover only the stenosed part of the PDA as this was a life-saving procedure, planned as the first, stabilizing intervention in a very hypoxic and hemodynamically unstable patient, in which the next step of total corrective surgery has been programmed to be performed during the same hospital admission. Our aim was to stabilize the patient and not create a long-lasting PDA as the source of pulmonary flow. At the same time, we tried to create as little as possible problems to the surgeons at stent explantation and not to add a supplemental stenosis of the left PA. For the same reason, we also accepted the angle created between the stent and the wall of the PDA at its distal end (Fig. IC), as implantation of a second stent to correct this could have caused stenosis of the left PA, which was not very large. 
The patient remained anticoagulated with enoxaparin, as part of the complex intensive care treatment, otherwise we would have only given aspirin.

Explantation of the stent two weeks later allowed us to perform a histologic analysis of the vascular wall (Figure 2).

\section{CASE 2 (IDIOPATHIC APHT)}

Patient PEA, I-year and 4-month old female toddler, was diagnosed at birth with an atrial septal defect (ASD) which spontaneously closed during the first year of life. At I year, during a regular check-up she was discovered with signs of severe PHT. Echocardiography and CTA excluded a CHD or a pulmonary
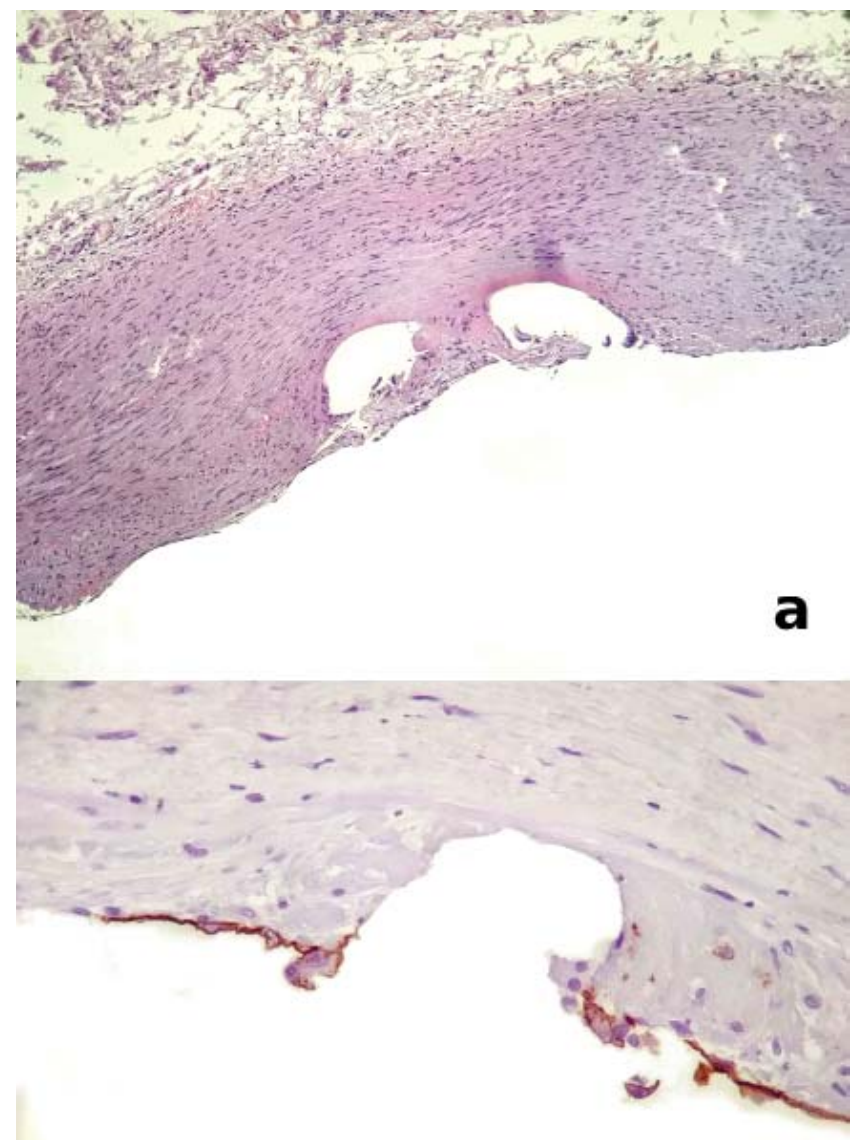

Figure 2. (a) The microscopic image of the vascular wall fragment included longitudinally, shows the marks of the explanted stent at the luminal side.A discrete chronic inflammatory infiltrate in the vascular intima, along with a moderate monocyte inflammatory infiltrate in the vascular media are also seen (hematoxylin-eosin stain, I0x objective). (b) Partial reendothelization evidenced by the anti-CD34 marker (immunohistochemical stain, DAB chromogen, $20 \times$ objective). cause of PHT. She was sent for detailed assessment to our clinic.

At admittance, the patient presented clinical signs of cardiac failure consistent with class IV of the Ross classification (malaise, fatigue, pale skin, palpebral and leg edema, tachycardia at 140 bpm, gallop rhythm, blood pressure of $100 / 70 \mathrm{mmHg}$, hepatomegaly). Echocardiography showed severely dilated right heart chambers with indirect signs of suprasystemic PHT (compression of the left heart chambers), dilated and hypertrophic RV with spontaneous echo contrast, severely decreased global contractility, and pericardial effusion lateral to the right chambers. Tricuspid insufficiency with a gradient of $60 \mathrm{mmHg}$ between the RV and the right atrium (probably underestimated due to the eccentric regurgitant jet, which made impossible to use this gradient for estimating the systolic pressure in the PA during the whole follow-up period) was also detected, along with moderate pulmonary insufficiency with a protodiastolic gradient of $46 \mathrm{mmHg}$, dilated PA, and a minimal jet over a tiny PDA (Figure 3).

Considering the clinical status and the echo information, pulmonary vasodilator therapy was started with an association of sildenafil and bosentan. The general status of the patient improved slightly over the following days, with a minor increase in the contractility of the RV.

One week after addmitance, as echo still showed signs of suprasystemic pulmonary arterial pressure, while the patient had no interatrial communcation and only a tiny PDA, it was decided to stent the PDA (i.e. to create an interventional Potts shunt). The procedure was performed under general anesthesia, with the

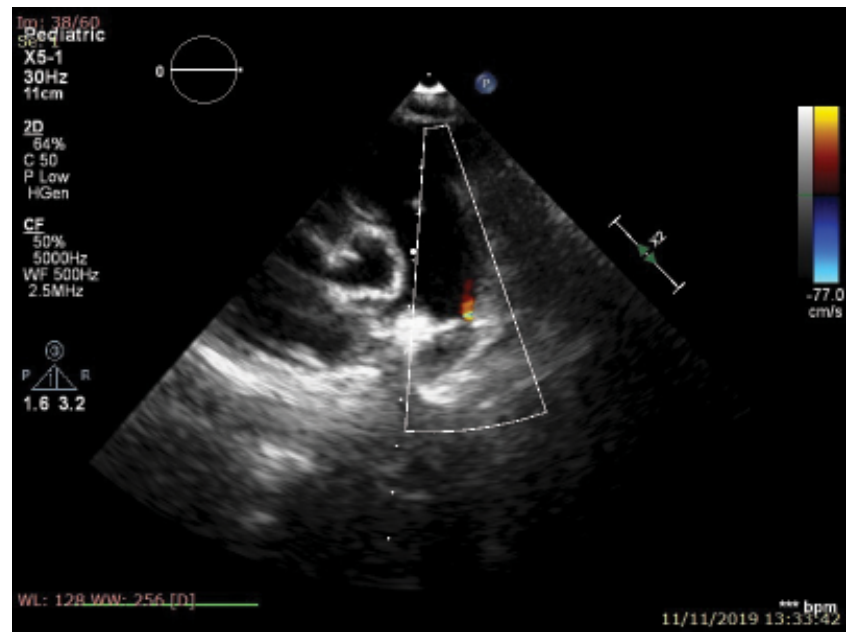

Figure 3. Preprocedural transthoracic echocardiogram, parasternal short axis: small patent ductus arteriosus in patient 2 . 
patient intubated and ventilated with 100\% oxygen. A $4 \mathrm{Fr}$ sheath was placed in the right femoral artery, changed afterwards for a long $35 \mathrm{~cm} 5 \mathrm{Fr}$ sheath. The PDA was localized from the aorta with a $4 \mathrm{Fr} \mathrm{BHW}$ catheter, allowing to image a long, but severly stenosed PDA at its pulmonary end. The PDA was crossed with a 0.014 " coronary angioplasty guidewire and predilatation with a $3.0 \times 20 \mathrm{~mm}$ semicompliant monorail balloon was performed at 12 atmospheres. This was followed by the implantation of a $4.5 \times 18 \mathrm{~mm}$ Resolute OnyxTM premounted drug eluting stent (Medtronic, CA, USA), expanded at 14 atmospheres. Progressive dilatation was performed with the aim of equalizing pulmonary and systemic pressures (offering a pop-off to the pulmonary blood flow with suprasystemic values, while maintain a sufficient anterograde flow in the PA, without excessive desaturation of the legs). A good final result was achieved, with the angiographic documentation of right- to- left shunting (Figure 4).

Preprocedural hemodynamic data showed saturations of $60.4 \%$ in the descending aorta (DAo) and $39.4 \%$ in the PA, and a "peak-to-peak" systemic gradient of $7 \mathrm{mmHg}$ between the PA and the DAo (PA 42/29/34 $\mathrm{mmHg}$, DAo: $35 / 30 / 30 \mathrm{mmHg}$ ). After the procedure, the PA-DAo gradient decreased to $3 \mathrm{mmHg}$, (PA $56 / 32 / 42 \mathrm{mmHg}$, DAo 53/34/39 $\mathrm{mmHg}$ ).

There were no procedural complications, but at the end of the intervention a sever pulmonary hypertensive crisis appeared, with severe desaturation, necessitating a short period of cardiac massage and a bolus of adrenalin, with rapid recovery of the vital signs and hemodynamic stabilisation. After the procedure, continous iv infusions of milrinone and noradrenaline were started (for II and 4 days, respectively), along with the previoulsy started sildenafil and bosentan therapy.

Over the next days and during later follow-up, the left cardiac chambers increased (due to increased blood return to the left heart chambers (Table I), left ventricular ejection fraction increased and the pressure in the PA decreased.

The patient was discharged 3 weeks after the intervention, on oral therapy with digoxin $0.8 \mathrm{mg}$ bid,

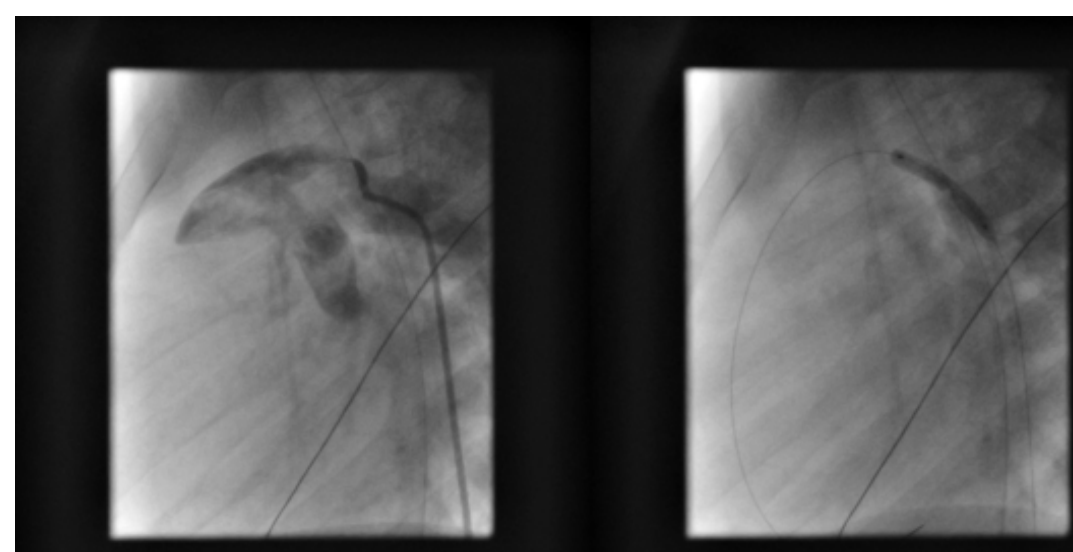

a

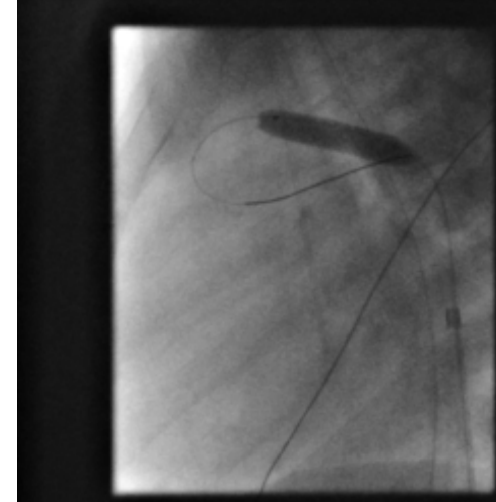

b

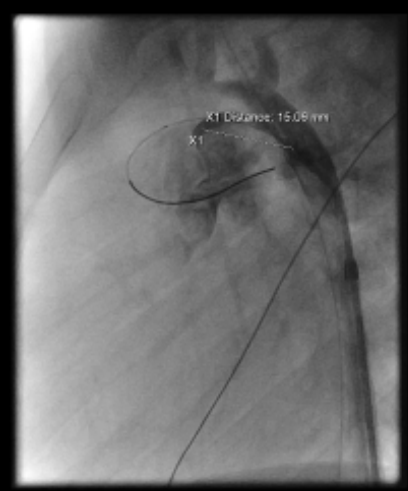

Figure 4. Angiograms of patient 2, in latero-lateral projection. Small PDA with a severe constriction at the pulmonary end (a); predilatation with a coronary artery balloon (b); measurement of the PDA length (c); stent implantation (d); final stent position (e), right-to-left flow over the stent (f). PDA - patent ductus arteriosus. 
Table I. Echocardiographic findings in patient 2

\begin{tabular}{|c|c|c|c|c|c|c|}
\hline & $\begin{array}{l}\text { Before stent } \\
\text { implantation }\end{array}$ & At 2 weeks & At 3 weeks & $\begin{array}{c}\text { At } 3 \text { month } \\
\text { (restless) }\end{array}$ & $\begin{array}{l}\text { At } 3 \text { month } \\
\text { (sedated) }\end{array}$ & $\begin{array}{c}\text { At } 8 \text { month } \\
\text { (restless) }\end{array}$ \\
\hline $\mathrm{LV}(\mathrm{d}) \mathrm{cm}$ & 0.8 & 2.48 & 2.27 & 2.4 & 2.74 & 2.4 \\
\hline $\mathrm{LV}(\mathrm{s}) \mathrm{cm}$ & $\mathrm{I}, 68$ & 1.84 & 1.7 & 1.84 & 1.96 & 1.84 \\
\hline LVEF (\%) & $35-40$ & 54 & 52 & 50 & 56 & 50 \\
\hline Sphericity index LV/RV cm & $0.8 / 3$ & - & - & $2.96 / 1.52$ & \begin{tabular}{|l|}
$3.42 / 3.19$ \\
\end{tabular} & $2.96 / 1.52$ \\
\hline Flow direction over the stent & - & $\begin{array}{l}\text { Bidirectional, } \\
\text { left-right during } \\
\text { sedation }\end{array}$ & $\begin{array}{l}\text { Bidirectional, } \\
\text { left-right during } \\
\text { sedation }\end{array}$ & Right- left & $\begin{array}{l}\text { Bidirectional, } \\
\text { left-right during } \\
\text { sedation }\end{array}$ & Right-left \\
\hline
\end{tabular}

spironolactone $12.5 \mathrm{mg}$ bid, aspirin $37.5 \mathrm{mg}$ qd, amlodipine $1.25 \mathrm{mg}$ bid, sildenafil 10 qid, and bosentan 10 mg bid.

At 3 month follow-up, during restlessness of the child, echocardiography showed dilated right cardiac chambers, increased PA pressures compared to the pervious assessment, with decreased left-to-right and increased right-to-left flow over the stented PDA. A CTA scan excluded stent restenosis. Echography under sedation showed a bidirectional flow over the stent, with a predominent left-to-right component and a gradient of $32 \mathrm{mmHg}$ between the RV and the right atrium. The bosentan dose was increased to 18 bid.

\section{Discussion}

Idiopathic aPHT has an unfavorable prognostic, both in children and adults. The response to drug therapy is often disappointing. Alternative therapies are relatively limited: lung transplantation (with mean survival time of $4.5-5.8$ years) $)^{13}$ and the surgical or interventional creation of a communication between the two circulations, either at atrial level (atrial septostomy) or at the level of the great arteries (Potts shunt, stenting a PDA).

Essentially, the last two methods are transforming a physiology of idiopathic aPHT in an Eisenmenger type of physiology, with increased survival chances, due to the existence of the pop-off mechanism towards the systemic circulation represented by the communications between the right and left heart. The price to pay is a systemic desaturation because of the right-to-left shunt at the level of these communications, along with the risk of paradoxical embolism.

Nowadays, the communication at the level of the great vessels is preferred, as by this method desaturation is limited to the inferior part of the body, while cerebral blood flow has normal saturations ${ }^{13}$.

Anterior studies demonstrated that in some cases, even when a PDA cannot be found echographically in a patient with idiopathic aPHT, this can still exist. For this reason, several centers have changed their protocol of assessing idiopathic aPHT patients, by carefully seeking for a potential PDA and stenting it when found ${ }^{13,14}$.

The indication is established only in patients with suprasystemic pressures in the pulmonary circulation.

The technique of stenting, relatively simple, requires an exact calibration of the diameter to which the stent is dilated, thus the PDA should function as a pop-off for the pulmonary circulation, but without impending the pulmonary anterograde circulation and with no excessive desaturation of the legs. This can be obtained by progressive dilatations of the stent, until an equalization of pulmonary and systemic pressures is obtained ${ }^{13,14}$.

In our patient, this goal was almost reached at the nominal stent diameter of $4.5 \mathrm{~mm}$ : the "peak-to-peak" gradient between PA and DAo pressures decreased from 7 to $3 \mathrm{mmHg}$. The maintenance of this $3-\mathrm{mmHg}$ gradient proved to be adequate, as under deep sedation the shunt tended to be mainly left-to-right.

Stent length must be chosen as to cover the total extent of the PDA, without creating an aortic or pulmonary stenosis ${ }^{13}$. In our patient, after measuring a PDA length of $15 \mathrm{~mm}$, we chose an $18 \mathrm{~mm}$ stent, which was finally slightly bulging into the left PA (Figure 5), without creating any obstruction at this level. As there was no stent protrusion towards the aorta, the crossing of the stent from its aortic end would not have been a problem in case of necessity.

The stent has to offer the possibility of post-dilatation with physiologic growth of the child. The choice of the most adequate stent is still a question of personal preference of the operator and availability in the catheterization laboratory. We have chosen a drug eluting stent, which can be dilated up to a diameter of $5.75 \mathrm{~mm}$. It remains an open question if the drug impregnation of the stent will be an advantage or a disadvantage on the long-term. Although a drug-eluting 


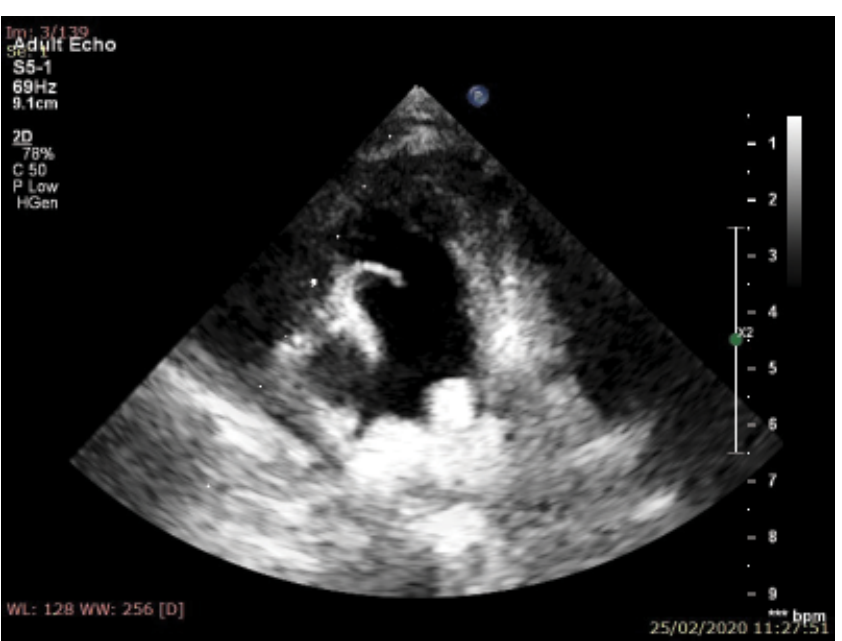

Figure 5. Postpocedural transthoracic echography in patient 2, short axis. Slight protrusion of the stent in the left pulmonary aretry, without realizing any stenosis.

stent was implanted, we preferred the administration of single antiplatelet therapy with aspirin.

The results were spectacular, as reported by all the other studies in the literature ${ }^{13,14}$, especially concerning the function and dimensions of the ventricles (Figure 6). This was obtained by decompression of the right heart chambers (reduction of the PA pressure by means of the pulmonary vasodilator medication, but also because of the pop-off created for the pulmonary pressure and blood flow, avoiding an acute RV hypertension), and left heart chambers (increase of the blood return to the left ventricle and decrease of the RV pressure). The evidence for the usefulness of the pop-off represented by the stented PDA is offered by the different physiology encountered in this patient during restless and rest periods, corresponding to the variations in PA pressure as the pop-off function of the PDA is used (Table I).

\section{CONCLUSIONS}

Stenting of the PDA is a feasible interventional procedure. The exact knowledge of the procedural objective could differentiate between failure and success. In case of proper patient selection, the implantation of a stent in the PDA can be of great help for the cCHD children with duct-dependent pulmonary circulation. PDA stenting can be an important bailout and could offer years of survival to the patient with idiopathic aPHT. While it needs a learning curve, careful preparation before introducing it in the daily practice of a cardiovascular center is essential.

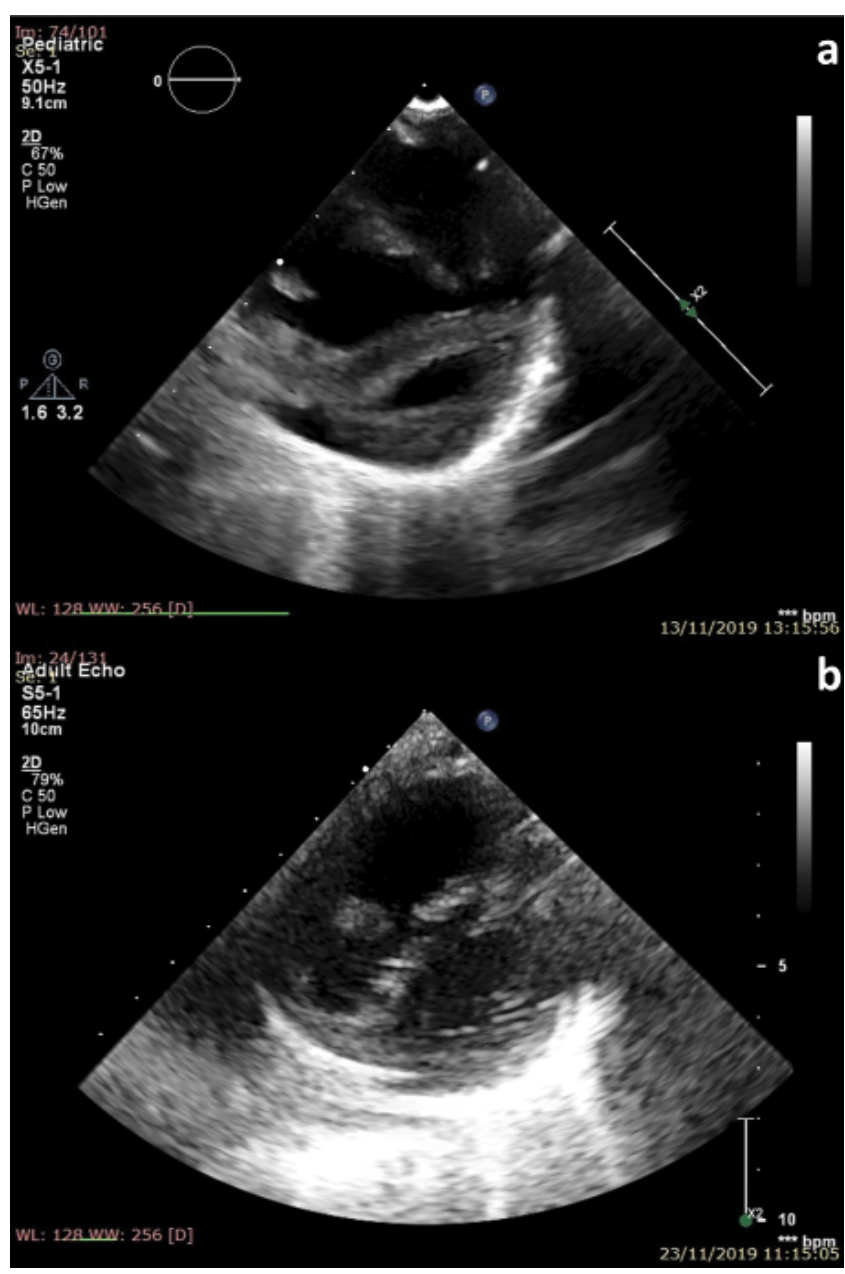

Figure 6. Transthoracic echocardiography in patient 2, parasternal short axis at ventricular level: compressed LV and dilated RV before the procedure (a); increased LV, but still dilated RV 8 months after the stent implantation. $L V$ - left ventricle, $R V$ - right ventricle.

Conflict of interest: none declared.

Financial support: This study was funded by the Romanian Academy of Medical Sciences and European Regional Development Fund, MySMIS I07I 24: Funding Contract 2/Axa I/3I.07.2017/ 107/24 SMIS.

\section{References:}

I. Gibbs JL, Rothman MT, Rees MR, Parsons JM, Blackburn ME, Ruiz CE. Stenting of the arterial duct: a new approach to palliation for pulmonary atresia. Br Heart J 1992;67: 240-5.

2. Dorobantu DM, Pandey R, Sharabiani MT, Mahani AS, Angelini GD, Martin RP, Stoica SC. Indications and results of systemic to pulmonary shunts: results from a national database. Eur J Cardiothorac Surg 2016;49: 1553-63.

3. Valdeomillos E, Jalal Z, Boudjemline $\mathrm{Y}$, Thambo JB, Filiale de cardiologie pediatrique et congenitale de la Societe francaise de c. Transcatheter ductus arteriosus stenting in paediatric cardiology: Indications, results and perspectives. Arch Cardiovasc Dis 2020; I I3: 129. 41 .

4. Glatz AC, Petit CJ, Goldstein BH, Kelleman MS, McCracken CE, McDonnell A, Buckey T, Mascio CE, Shashidharan S, Ligon RA, Ao J, Whiteside W, Wallen WJ, Metcalf CM, Aggarwal V, Agrawal H, Qureshi A. Comparison Between Patent Ductus Arteriosus Stent 
and Modified Blalock-Taussig Shunt as Palliation for Infants With Ductal-Dependent Pulmonary Blood Flow: Insights From the Congenital Catheterization Research Collaborative. Circulation 2018;137: 589-60I.

5. Feltes TF, Bacha E, Beekman RH, Cheatham JP, Feinstein JA, Gomes AS, Hijazi ZM, Ing FF, de Moor M, Morrow WR, Mullins CE, Taubert KA, Zahn EM, American Heart Association Congenital Cardiac Defects Committee of the Council on Cardiovascular Disease in the Young; Council on Clinical Cardiology; Council on Cardiovascular Radiology and Intervention; American Heart Association. Indications for cardiac catheterization and intervention in pediatric cardiac disease: a scientific statement from the American Heart Association. Circulation 201 I; 123: 2607-52.

6. Alwi M. Stenting the ductus arteriosus: Case selection, technique and possible complications. Ann Pediatr Cardiol 2008; I: 38-45.

7. Alwi M, Mood MC. Stenting of Lesions in Patent Ductus Arteriosus with Duct-Dependent Pulmonary Blood Flow: Focus on Case Selection, Techniques and Outcome. Interv Cardiol Clin 2013;2: 93-II3.

8. Lin YJ, Liang CD, Fang CY, Yip HK, Ng SH, Ko SF. Multidetectorrow $\mathrm{CT}$ evaluation of tortuous ductus arteriosus for stent implantation in neonates with duct-dependent pulmonary circulation: preliminary experience in 4 cases. Acta Cardiol Sin. 2010;26: I I I-8.
9. Aggarwal V, Petit CJ, Glatz AC, Goldstein BH, Qureshi AM. Stenting of the ductus arteriosus for ductal-dependent pulmonary blood flow-current techniques and procedural considerations. Congenit Heart Dis 2019; I4: I10-5.

10. Rehman R, Marhisham MC, Alwi M. Stenting the complex patent ductus arteriosus in tetralogy of Fallot with pulmonary atresia: challenges and outcomes. Future Cardiol 2018; |4: 55-73.

II. Roggen M, Cools B, Brown S, Boshoff D, Heying R, Eyskens B, Gewillig M. Can ductus arteriosus morphology influence technique/ outcome of stent treatment? Catheter Cardiovasc Interv 2020;95: I |49-57.

12. Haas NA, Fernandez-Rodriguez S, Dalla Pozza R, Fischer M, Ulrich $S$, Jakob A, Lehner A. Microcatheter-assisted stenting of the tortuous vertical ductus arteriosus via femoral access in a duct-dependent pulmonary circulation. Int J Cardiol 2019;285: 103-7.

13. Boudjemline Y, Patel M, Malekzadeh-Milani S, Szezepanski I, Levy $M$, Bonnet D. Patent ductus arteriosus stenting (transcatheter Potts shunt) for palliation of suprasystemic pulmonary arterial hypertension: a case series. Circ Cardiovasc Interv 2013;6: el 8-20.

14. D'Alto M, Santoro G, Palladino MT, Parisi F, Russo MG. Patent ductus arteriosus stenting for palliation of severe pulmonary arterial hypertension in childhood. Cardiol Young 2015;25: 350-4. 